\title{
Ventilator Associated Pneumonia in Patients Using Endotracheal Tube with Intermittent Subglottic Secretion Drainage and Using Endotracheal Tube without Drainage
}

Md. Zubyeer Ali Sheikh ${ }^{1 *}$, A. K. Qumrul Huda ${ }^{2}$, Montosh Kumar Mondal ${ }^{3}$, Md. Mohiuddin Majed Chy ${ }^{4}$, Mohammad Mahbubuzzaman ${ }^{4}$, Shah Sarwar Jahan ${ }^{4}$, Md. Saiful Islam ${ }^{5}$

${ }^{1}$ Assistant Professor, Department of Anesthesia and Intensive Care Medicine, Khulna City Medical College Hospital, KDA Ave, Khulna, Bangladesh

${ }^{2}$ Professor, Department of Anesthesia, Analgesia and Intensive Care Medicine, BSMMU, Dhaka, Bangladesh

${ }^{3}$ Associate Professor, Department of Anesthesia, Analgesia and Intensive Care Medicine, BSMMU, Dhaka, Bangladesh

${ }^{4}$ Anaesthesiologist, National Institute of Trauma and Orthopedic Rehabilitation, Dhaka, Bangladesh

${ }^{5}$ Assistant Professor Department of Anesthesia, Green Life Medical College, Dhaka, Bangladesh

DOI: $10.36347 /$ sjams.2021.v09i04.002

| Received: 28.02.2021 | Accepted: 17.03.2021 | Published: 02.04.2021

*Corresponding author: Md. Zubyeer Ali Sheikh

Abstract

Original Research Article

Background: Ventilator-associated pneumonia (VAP) is the leading healthcare-acquired infection (HAI) among mechanically ventilated patients in intensive care units (ICU). The influence of subglottic secretion drainage (SSD) in reducing VAP remains controversial. Aim and Objective: This prospective study was intended to find the effectiveness of endotracheal tube (ETT) with subglottic suction device (for intermittent subglottic secretion drainage) in reducing the risk of VAP. Study Design: Prospective observational study. Patients \& Methods: The study consecutively included 42 adult patients on mechanical ventilation from ICU Unit of BSMMU, Dhaka during the study period. Patients were divided into two groups one with endotracheal tube with subglottic suction device (SSD) (Group-A, $\mathrm{n}=21$ ) and another with conventional endotracheal tube (Group-B, $\mathrm{n}=21$ ). Data were collected by taking detailed history, clinical examination, investigation including tracheal aspirate culture to find the presence or absence of ventilator-associated pneumonia (VAP) on ventilated patients. The incidence of VAP was compared between the Group-A and Group-B and the relative risk (RR) of developing VAP in patients with SSD were calculated. Results: The Group-A and Group-B were almost alike in terms of demographic characteristics (age and sex). Smoking habit was almost identical between groups. Reason of ICU admission was no different between groups $(\mathrm{p}=0.263)$. The average duration of mechanical ventilation was also statistically similar. Associated co-morbidities were also similar in distribution between groups. Six out of 21(28.6\%) patients in the Group-A and 12(57.1\%) out of 21 patients in the Group-B developed VAP. The risk of developing VAP in the Group-A was calculated to be 0.53 or $53 \%(95 \% \mathrm{CI}=$ $.25-1.09)$ less compared to that in the Group-B. $(\mathrm{p}=0.061)$. Of the 6 patients who developed VAP in the Group-A 4 $(66.7 \%)$ had late VAP and the rest early VAP, but in the Group-B out of 12 patients $11(91.6 \%)$ patients had late VAP. The predominant microorganisms grown was acinatobacter (in both groups). Conclusion: The use of an ETT with intermittent SSD in a patient on mechanical ventilator helps to reduce ventilator associated pneumonia.

Keywords: Mechanical ventilator, Infection, Subglottic secretion, Endotreal tube, Ventilator associated pneumonia. Copyright $\odot 2021$ The Author(s): This is an open-access article distributed under the terms of the Creative Commons Attribution 4.0 International License (CC BY-NC 4.0) which permits unrestricted use, distribution, and reproduction in any medium for non-commercial use provided the original author and source are credited.

\section{INTRODUCTION}

Pneumonia is the most common infectious cause of death and one of the top ten causes of death worldwide [1]. In the ICU almost 80 to $90 \%$ episodes of nosocomial pneumonia (NP) occur in patients who are being mechanically ventilated for other reasons, and are termed ventilator-associated pneumonia (VAP).
Ventilator-associated pneumonia (VAP) is defined as the occurrence of pneumonia in patients undergoing mechanical ventilation after 48 hours. Clinical definition of VAP requires the presence of a new radiographic infiltrate and at least two of three major clinical findings - fever $>38^{\circ} \mathrm{C}$, purulent tracheal secretions, and leukocytosis or leucopenia. 
Zubyeer Ali Sheikh et al; Sch J App Med Sci, Apr, 2021; 9(4): 506-511

The leakage of contaminated secretions around the endotracheal tube cuff allows bacterial entry into the trachea $[2,3]$. The conventional ETT limits the draining of secretions that leak around the cuff, favors bacterial multiplication and offers a focus for bacterial adherence and colonization.

The time of onset of VAP suggests the etiology of VAP, making it useful to distinguish earlyonset VAP from late-onset VAP. In the recent American Thoracic Society/Infectious Disease Society of America (ATS/IDSA) Guidelines, Ventilatorassociated pneumonia which developed within 4 days of intubation and mechanical ventilation is early onset VAP and which developed after 4 days of intubation and mechanical ventilation is late onset VAP.

According to the Centers for Disease Control and Prevention published guidelines on the prevention of VAP [4], VAP can be reduced by (a) changing the breathing circuits of ventilators only when they malfunction or are visibly contaminated, (b) preferential use of oro-tracheal rather than naso-tracheal tubes, (c) use of noninvasive ventilation, (d) use of an endotracheal tube with a dorsal lumen to allow drainage of respiratory secretion. A specially designed endotracheal tube with a separate dorsal lumen that opens immediately above the endotracheal tube cuff has been claimed to better drain subglottic secretions thereby reducing the colonization of offending bacteria. In two single-center randomized controlled trials [5, 6] and in one observational study [7], subglottic secretion drainage (SSD) successfully reduced the incidence of VAP. However these positive results were not confirmed in three other single-center trials [8-10].

\section{OBJeCtives \\ General Objective}

Observation of the effectiveness of endotracheal tube with subglottic suction device (for intermittent subglottic secretion drainage) in reducing the risk of ventilator-associated pneumonia.

\section{Specific Objectives}

- To see the rate of ventilator associated pneumonia in patients using endotracheal tube with subglottic secretion drainage.

- To see the rate of ventilator associated pneumonia in patients using endotracheal tube without subglottic secretion drainage.

- To compare early onset ventilator associated pneumonia and late onset ventilator associated pneumonia in both groups.

\section{MeTHODS}

Study Design: This was a prospective observational study.
Place of study: The study was carried out in the Department of Anesthesia, Analgesia and Intensive Care Medicine, BSMMU, Dhaka.

\section{Enrolment Criteria Inclusion Criteria}

All adult patients who were placed on mechanical ventilator for more than 48 hours.

\section{Exclusion Criteria}

- $\quad$ Time interval of onset of pneumonia less than 48 hours after placement on mechanical ventilator

- Patients on NIPPV (Non-invasive positive pressure ventilation)

- Diagnosed case of pneumonia

- Chest trauma patients

- Severely immunocompromised patients (known HIV infection, cancer patients on chemotherapy or radiotherapy)

The study consecutively included 42 adult patients on mechanical ventilation from ICU Unit of BSMMU. Patients were divided into two groups one with endotracheal tube with subglottic suction device (SSD) (Group-A, $\mathrm{n}=21$ ) and another with conventional endotracheal tube (Group-B, $\mathrm{n}=21$ ). Data were collected by taking detailed history, clinical examination, investigation including tracheal aspirate culture to find the presence or absence of ventilatorassociated pneumonia (VAP) on ventilated patients. The incidence of VAP was compared between the Group-A and Group-B and the relative risk (RR) of developing VAP in patients with SSD were calculated.

\section{RESULT}

In the present study a total of 42 mechanically ventilated patients out of 335 patients admitted in the intensive care unit (ICU) of BSMMU were selected on the basis of selection criteria. Study patients with Hi Lo Evac ETT (Group-A) and conventional ETT (Group-B) were selected in consecutive manner. Out of 42 patients 21 patients were on Group-A, other 21 patients were on Group-B. In the Group-A subglottic secretions were suctioned manually with a10 $\mathrm{ml}$ syringe at an intended frequency of single suction per hour. All those patients were followed up till 28 days, 2 days after extubation or death which one came first after they met the selection criteria. The findings obtained from data analysis are presented below.

\section{Demographic Characteristics}

Demographic characteristics like age and sex and smoking habit were almost identically distributed between groups $(p=0.872, p=0.747$ and $p=0.491$ respectively). Reason of ICU admission was no different between groups $(p=0.263)$. The average duration of mechanical ventilation, although, was less in the Group-A compared to the Group-B, the difference was not statistically significant $(p=0.307)$ (Table-1). 
Zubyeer Ali Sheikh et al; Sch J App Med Sci, Apr, 2021; 9(4): 506-511

Table-1: Comparison of patients by their baseline characteristics

\begin{tabular}{|l|l|l|l|}
\hline \multirow{2}{*}{ Baseline characteristics } & \multicolumn{2}{l|}{ Groups } & \multirow{2}{*}{ P-value } \\
\cline { 2 - 3 } & Group-A (n=21) & Group-B (n=21) & \\
\hline Age (years) & & \\
\hline Sex* & $44.5 \pm 14.1$ & $43.7 \pm 19.5$ & 0.872 \\
\hline Male & & & \\
\hline Female & $13(61.9)$ & $14(66.7)$ & \\
\hline Smoking habit* & $8(38.1)$ & $7(33.3)$ & 0.747 \\
\hline Reason of ICU admission* & $10(47.6)$ & $7(36.8)$ & 0.491 \\
\hline Type II Respiratory failure & & & \\
\hline Grade IV unconciousness & $8(38.1)$ & $8(38.1)$ & \\
\hline Post OP haemodynamic instability & $2(9.5)$ & $2(9.5)$ & \\
\hline Electrolyte imbalance & $9(42.9)$ & $5(23.8)$ & 0.263 \\
\hline Laboured breathing & $0(0.0)$ & $2(9.5)$ & \\
\hline Type I Respiratory failure & $2(9.5)$ & $3(7.1)$ & \\
\hline Duration of mechanical ventilation ${ }^{\#}$ (days) & $9.1 \pm 6.5$ & $3(7.1)$ & \\
\hline
\end{tabular}

Figures in the parentheses indicate corresponding \%;

*Chi-squared Test $\left(\chi^{2}\right)$ was done to analyze the data; **Fisher's Exact Test was done to analyze the data. \#Data were analyzed using Unpaired t-Test and were presented as mean \pm SD.

\section{Associated Co-Morbidities}

Associated co-morbidities were similar in distribution between the study groups $(\mathrm{p}>0.05$ in each case). APACHE II score during admission, however, was significantly lower in the Group-A than that in the Group-B ( $\mathrm{p}=0.010)$, but GCS was not found vary between groups $(\mathrm{p}=0.139)($ Table-2).

Table-2: Comparison of patients by their comorbid conditions

\begin{tabular}{|l|l|l|l|}
\hline \multirow{2}{*}{ Co-morbid conditions } & \multicolumn{2}{l}{ Group } & \multirow{2}{*}{ P-value } \\
\cline { 2 - 3 } & Group-A $(\mathrm{n}=21)$ & Group-B $(\mathrm{n}=21)$ & \\
\hline COPD $^{* *}$ & $1(4.8)$ & $2(9.5)$ & 0.500 \\
\hline $\mathrm{DM}^{* *}$ & $2(9.5)$ & $7(33.3)$ & 0.065 \\
\hline $\mathrm{HTN}^{*}$ & $8(38.1)$ & $9(42.9)$ & 0.753 \\
\hline $\mathrm{CKD}^{* *}$ & $2(9.5)$ & $3(14.3)$ & 0.500 \\
\hline RTA $^{* *}$ & $3(14.3)$ & $2(9.5)$ & 0.500 \\
\hline APACHE II score during admission $^{\#}$ & $11.7 \pm 5.9$ & $18.0 \pm 8.8$ & 0.010 \\
\hline GCS score $^{\#}$ & $11.3 \pm 3.2$ & $9.8 \pm 3.1$ & 0.139 \\
\hline
\end{tabular}

Figures in the parentheses indicate corresponding \%;

*Chi-squared Test $\left(\chi^{2}\right)$ was done to analyze the data; **Fisher's Exact Test was done to analyze the data. \#Data were analyzed using Unpaired t-Test and were presented as mean \pm SD.

\section{Rate of VAP in Groups}

Six out of $21(28.6 \%)$ patients in the Group-A (Hi-Lo Evac) and $12(57.1 \%)$ out of 21 patients in the
Group-B (conventional ETT without SSD) developed VAP (Table-3).

Table-3: Rate of VAP developed between groups

\begin{tabular}{|l|l|l|}
\hline \multirow{2}{*}{ VAP* } & Group \\
\cline { 2 - 3 } & Group-A $(\mathrm{n}=21)$ & Group-B $(\mathrm{n}=21)$ \\
\hline Developed & $6(28.6)$ & $12(57.1)$ \\
\hline Not developed & $15(71.4)$ & $9(42.9)$ \\
\hline
\end{tabular}

Figures in the parentheses indicate corresponding \%;

Association between ventilator-associated pneumonia (VAP) and endotracheal tube (ETT) used:

The risk of developing VAP in the Group-A was calculated to be 0.53 or $53 \%$ (95\% CI $=0.25-1.09)$ less compared to that in the Group-B $(\mathrm{p}=0.061)$ (Table-4). 
Zubyeer Ali Sheikh et al; Sch J App Med Sci, Apr, 2021; 9(4): 506-511

Table-4: Comparison rate of developing VAP between groups

\begin{tabular}{|l|l|l|l|l|}
\hline \multirow{2}{*}{ VAP* } & \multicolumn{2}{|l|}{ Group } & \multirow{2}{\text{RR}}{ P-value } \\
\cline { 2 - 3 } & $\begin{array}{l}\text { Group-A } \\
(\mathrm{n}=21)\end{array}$ & $\begin{array}{c}\text { Group-B } \\
(\mathrm{n}=21)\end{array}$ & \\
\hline Developed & $6(28.6)$ & $12(57.1)$ & $0.53(0.25-1.09)$ & 0.061 \\
\hline Not developed & $15(71.4)$ & $9(42.9)$ & & \\
\hline
\end{tabular}

Figures in the parentheses indicate corresponding \%;

* Chi-squared Test $\left(\chi^{2}\right)$ was done to analyze the data.

\section{Type of VAP}

Of the 6 patients who developed VAP in the Group-A 4(66.7\%) had late onset VAP and 2(33.3\%) early-onset VAP, but in the Group-B out of 12 patients 11(91.6\%) patients had late VAP (Fig-1).

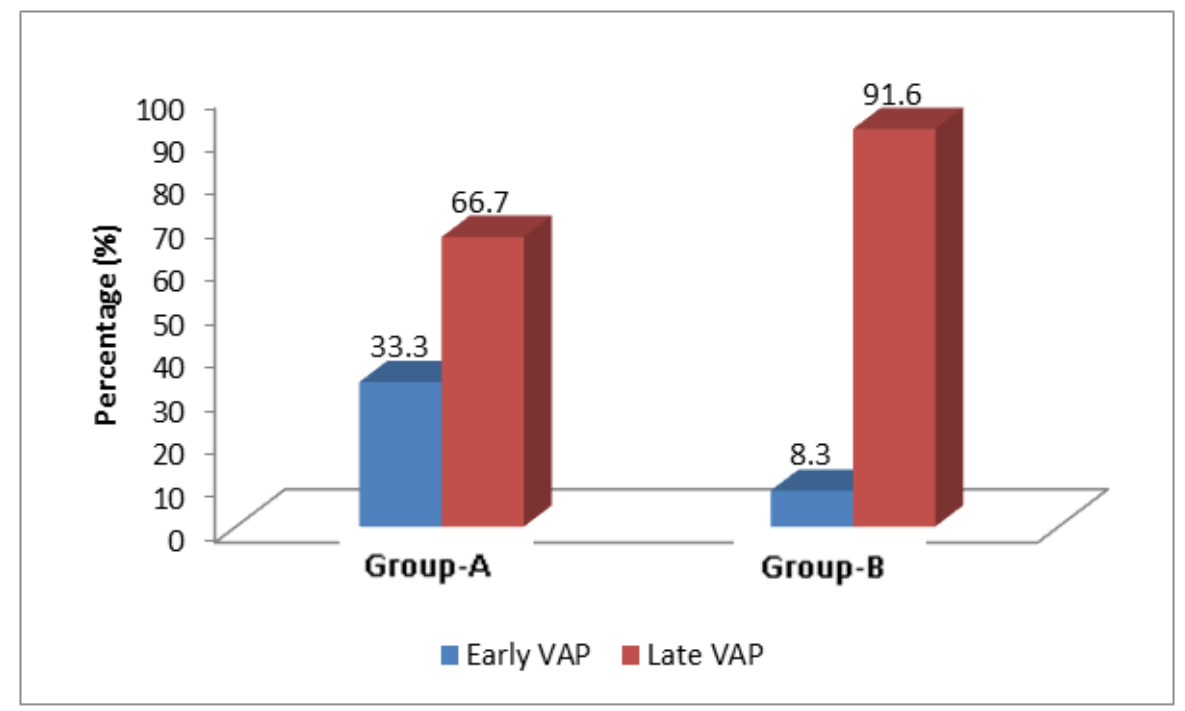

Fig-1: Distribution of early and late ventilator-associated pneumonia (VAP)

Association between type of ETT used and growth of microorganism:

Growth of organisms found on culture of tracheal aspirate is shown in Table-5. A significant proportion of patients of Group-B demonstrated growth of microorganisms compared to Group-A ( $\mathrm{p}=0.061)$ (Table-6).

Table-5: Rate of growth of microorganisms between groups

\begin{tabular}{|l|l|l|}
\hline Growth of organisms* & Group \\
\cline { 2 - 3 } & Group-A (n=21) & Group-B (n=21) \\
\hline No growth & $15(71.4)$ & $9(42.9)$ \\
\hline Growth & $6(28.6)$ & $12(57.1)$ \\
\hline
\end{tabular}

Figures in the parentheses indicate corresponding \%;

Table-6: Association between type of ETT used and growth of microorganism

\begin{tabular}{|l|l|l|l|}
\hline Growth of organisms* & Group & \multirow{2}{*}{ P-value } \\
\cline { 2 - 3 } & Group-A ( $\mathrm{n}=21)$ & Group-B (n=21) & \\
\hline No growth & $15(71.4)$ & $9(42.9)$ & 0.061 \\
\hline Growth & $6(28.6)$ & $12(57.1)$ & \\
\hline
\end{tabular}

Figures in the parentheses indicate corresponding \%;

*Chi-squared $\left(\chi^{2}\right)$ Test was employed to analyze the data.

\section{Pattern of Microorganisms Grown}

Fig-2 shows the pattern of microorganisms was grown between groups. The predominant bacteria found was acinatobacter in both groups same frequency. In group A (SSD group) total growth 6, among them
$5(83.33 \%)$ was acinatorbacter, 1(16.66\%) Group B streptococcus. In Group B (conventional ETT group) total growth 12, among them $10(83.33 \%)$ was acinatorbacter, $1(8.33 \%) \quad$ klebsiella, $1(8.33 \%)$ pseudomonas. 


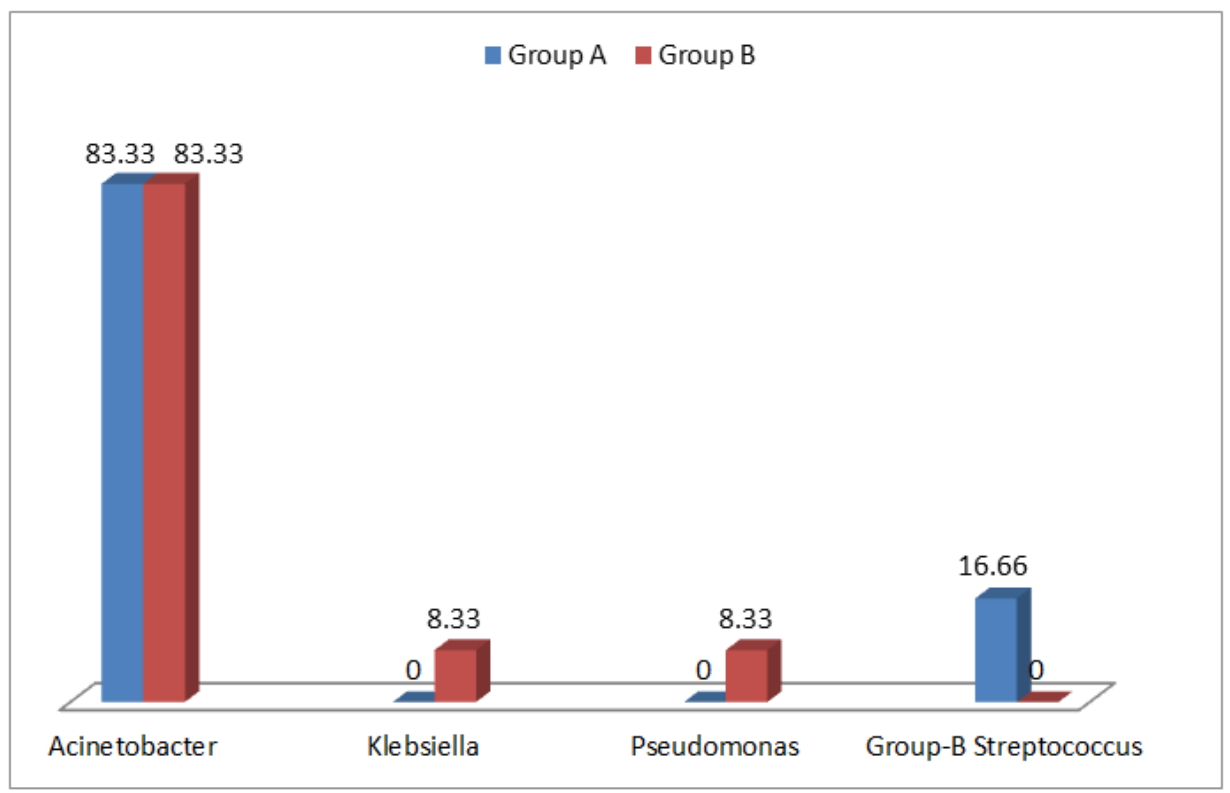

Fig-2: Pattern of microorganisms grown on culture

\section{DisCUSSIONS}

Worldwide the staggeringly high incidence of ventilator-associated pneumonia (VAP) (between $8 \%$ and $68 \%$ ) [11] in ICU patients with consequent high case fatality rate (20-50\%) [12] suggest that preventing VAP in critically ill patients is a priority. One of the problems contributing to the development of VAP is the presence of the ETT tube itself. It impedes the respiratory systems normal defense mechanisms and creates a gateway for bacterial colonization in the lungs. The ETT balloon or cuff provides a platform where contaminated secretions can collect and pool. These pooled contaminants are known as subglottic secretions and can be aspirated in the lower respiratory tract [13]. The microaspiration of these secretions is a preventable etiological factor in the development of VAP [14]. Therefore, aspiration of subglottic secretions is an important first step for preventing both early- and lateonset VAP in ICU patients under ventilator support [15].

In the present study the incidence of VAP in the Group-A (ETT with SSD group) was $28.6 \%$ as compared to $57.1 \%$ in the Group-B (conventional ETT without SSD). The risk of developing VAP was 53\% (95\% CI $=0.25-1.09)$ less compared to that in the control group. $(\mathrm{p}=0.061)$. \{ Here $\mathrm{p}$ value 0.061 statistically not significant is due to very small sample size\}. As all the baseline characteristics (age, sex, smoking habit, reasons for ICU admission, duration MV, associated comorbidities, GCS score) except APACHE-II score during admission were almost identically distributed between groups, the outcome obtained could be attributed to use of intermittent subglotic suction device. Quite consistent with our findings Safdari et al., 2014 in a study in Iran demonstrated that intermittent SSD with inspiratory pause maneuver resulted in a significant reduction in the incidence of early-onset VAP (26.3\% vs. $47.4 \%)$ in an unselected population of ICU patients.

Likewise Lacherde et al., 2010 and Smulders et al., 2002 in their study about intermittent SSD with Hi Lo evac ETT, reported VAP reduction, while Liu et al., 2006 in their studies about continuous SSD with $H i$ Lo evac ETT, observed more VAP reduction in the study group than that in the control group. Muscedere and colleagues in their systematic review and metaanalysis of 13 randomized clinical trials, have reported $50 \%$ reduction in VAP incidence by using the $\mathrm{Hi} \mathrm{LO}$ evac ETT [16].

Chow et al., 2012 in their pilot randomized trial about the effect of continuous oral suctioning on the development of VAP, reported a significant reduction in VAP incidence. So from the findings of the present study and those of other studies (already discussed), it is assumed that the reduction of VAP in the ICU patients undergoing mechanical ventilation is very much dependant on the removal of accumulated secretions from the subglottic space as done by $\mathrm{Hi}$ Lo evac ETT with SSD and oral suctioning.

\section{CONCLUSION}

The study thus concluded that a significant reduction in the incidence of VAP in ICU patients under mechanical ventilation could be achieved by using $\mathrm{Hi}$ Lo Evac endotracheal tube with SSD.

\section{RECOMMENDATION}

Future clinical trials with a larger sample size are recommended to validate the findings of the present study. Till such data are available, clinicians must learn to make the best use of innovative methods like that used in the present study. 
Zubyeer Ali Sheikh et al; Sch J App Med Sci, Apr, 2021; 9(4): 506-511

\section{REFERENCES}

1. World Health Organization. The top 10 causes of death Available at: http://www.who.int/mediacentre/factsheets/fs310/e n/. Accessed October 31, 2011.

2. Chastre J, Fagon JY. Ventilator-associated pneumonia. American journal of respiratory and critical care medicine. 2002 Apr 1;165(7):867-903.

3. Rello J, Diaz E, Rodriguez A. Advances in the management of pneumonia in the intensive care unit: review of current thinking. Clinical Microbiology and Infection. 2005 Oct;11:30-8.

4. Tablan OC, Anderson LJ, Besser RE, Bridges CB, Hajjeh RA. 'Healthcare Infection Control Practices Advisory Committee, Centers for Disease Control and Prevention. Guidelines for preventing healthcare-associated pneumonia, 2003: recommendations of the CDC and the Healthcare Infection Control Practices Advisory Committee,' M.M.W.R., Recomm Rep, 2004; 53, RR-3, 1-66.

5. Mahul PH, Auboyer C, Jospe R, Ros A, Guerin C, Khouri EI, Z, Galliez M, Dumont, A, Gaudin O. 'Prevention of nosocomial pneumonia in intubated patients: respective role of mechanical subglottic secretions drainage and stress ulcer prophylaxis. Intensive Care Med. 1992;18:20-25.

6. Smulders K, Van der Hoeven H, Weers-Pothoff I, Vandenbroucke-Grauls C. A randomized clinical trial of intermittent subglottic secretion drainage in patients receiving mechanical ventilation. Chest. 2002 Mar 1;121(3):858-62.

7. Rello J, Sonora R, Jubert P, Artigas A, Rué M, Vallés J. Pneumonia in intubated patients: role of respiratory airway care. American journal of respiratory and critical care medicine. 1996 Jul;154(1):111-5.

8. Bouza E, Pérez MJ, Munoz P, Rincón C, Barrio JM, Hortal J. Continuous aspiration of subglottic secretions in the prevention of ventilatorassociated pneumonia in the postoperative period of major heart surgery. Chest. 2008 Nov 1;134(5):938-46.
9. Kollef MH, Skubas NJ, Sundt TM. A randomized clinical trial of continuous aspiration of subglottic secretions in cardiac surgery patients. Chest. 1999 Nov 1;116(5):1339-46.

10. Valles J, Artigas A, Rello J, Bonsoms N, Fontanals D, Blanch L, Fernandez R, Baigorri F, Mestre J. Continuous aspiration of subglottic secretions in preventing ventilator-associated pneumonia. Annals of internal medicine. 1995 Feb 1;122(3):179-86.

11. Labeau S, Vandijck DM, Claes B, Van Aken P, Blot SI, Executive Board of the Flemish Society for Critical Care Nurses. Critical care nurses' knowledge of evidence-based guidelines for preventing ventilator-associated pneumonia: an evaluation questionnaire. American Journal of Critical Care. 2007 Jul;16(4):371-7.

12. Davis KA. Ventilator-associated pneumonia: a review. Journal of Intensive Care Medicine. 2006 Jul;21(4):211-26.

13. O'Keefe- McCarthy S, Santiago C, Lau G. Ventilator- associated pneumonia bundled strategies: an evidence- based practice. Worldviews on Evidence- Based Nursing. 2008 Dec;5(4):193-204.

14. Safdar N, Crnich CJ, Maki DG. The pathogenesis of ventilator-associated pneumonia: its relevance to developing effective strategies for prevention. Respiratory care. 2005 Jun 1;50(6):725-41.

15. Lacherade JC, De Jonghe B, Guezennec P, Debbat K, Hayon J, Monsel A, Fangio P, Appere de Vecchi C, Ramaut C, Outin H, Bastuji-Garin S. Intermittent subglottic secretion drainage and ventilator-associated pneumonia: a multicenter trial. American journal of respiratory and critical care medicine. 2010 Oct 1;182(7):910-7.

16. Muscedere J, Rewa O, Mckechnie K, Jiang X, Laporta D, Heyland DK. Subglottic secretion drainage for the prevention of ventilator-associated pneumonia: a systematic review and metaanalysis. Critical care medicine. 2011 Aug $1 ; 39(8): 1985-91$ 